\title{
Cord blood 25-hydroxy Vitamin D and Fluoride in newborn with congenital anomalies
}

\author{
Abhra Ghosh', Jagriti Bhardwaj² \\ ${ }^{1}$ Assistant Professor, Department of Biochemistry, Dayanand Medical College \& Hospital, Ludhiana, ${ }^{2}$ Senior Resident, \\ Department of Gynecology \& Obstetrics, ESIC Basaidharapur, New Delhi
}

Background: It is well known that deficiency of 25-hydroxy Vitamin D can cause various musculoskeletal manifestations as well as metabolic, non-musculoskeletal abnormalities. There may be a chance that hypovitaminosis $D$ can act as a causative factor for congenital anomalies. Aims and Objective: The present study was planned to evaluate the level of 25-hydroxy Vitamin D in cord blood in cases of congenital anomalies and its association with cord blood fluoride levels in newborns with visible congenital anomalies. Materials and Methods: Thirty newborns with visible congenital anomalies were included in group I and thirty healthy newborns without any congenital anomalies were included in group II. Ten $\mathrm{mL}$ cord blood was collected from the placental end of umbilical cord immediately after delivery of the baby and serum was separated. Serum 25-hydroxy Vitamin D and fluoride were analyzed by standard methods. Statistical analysis: Results were expressed as Mean \pm SD. Unpaired ' $t$ ' test and Pearson correlation test were applied. Data were considered to be significant if $p<0.05$. Results: Serum 25-hydroxy Vitamin D levels were significantly decreased in babies with congenital anomalies $(p=0.001)$ and show a significant negative association with fluoride. Anomalies related to central nervous system and musculoskeletal systems had the lowest 25-hydroxy Vitamin D levels and highest serum fluoride levels than other anomalies of other systems. Conclusion: Fluoride can acts as an inhibitor for activation of calciferol causing a decrease in 25-hydroxy Vitamin D levels. Thus 25-hydroxy Vitamin D is an important micronutrient for proper development of the fetus and association of it with excess fluoride can cause congenital anomalies.

Key words: 25 - Hydroxy Vitamin D; Fluoride; Congenital Anomalies

\section{Access this article online}

Website:

http://nepjol.info/index.php/AJMS

DOI: 10.3126/ajms.v11i3.28101

E-ISSN: 2091-0576

P-ISSN: 2467-9100

Copyright (c) 2020 Asian Journal of Medical Sciences

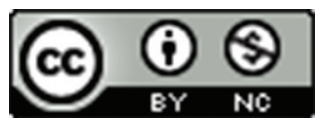

This work is licensed under a Creative Commons Attribution-NonCommercial 4.0 International License.

\section{INTRODUCTION}

Congenital anomalies (birth defects) can be defined as structural or functional abnormalities (e.g., metabolic disorders) that occur during intrauterine life and can be diagnosed prenatally, at the time of birth or after birth and later in life. There are various factors causing congenital anomalies including socioeconomic and demographic factors ${ }^{1,2}$ genetic factors, ${ }^{3}$ various infections like rubella, cytomegalovirus, toxoplasmosis, Zika virus etc., ${ }^{46}$ deficiency of various micronutrients like iodine, folic acid, iron, vitamin $\mathrm{A}^{7}$ and lastly environmental factors like exposure to different cytotoxic chemicals and teratogenic compounds. ${ }^{8}$

25-hydroxy Vitamin D is an important micronutrient and its deficiency and insufficiency are common across the globe. Various studies have revealed the high prevalence of 25-hydroxy Vitamin D deficiency in women of all age groups, including antenatal and lactating mothers. ${ }^{9-11} \mathrm{It}$ is well known that deficiency of 25-hydroxy Vitamin D can cause various musculoskeletal manifestations. But various metabolic, non-musculoskeletal effects of 25-hydroxy Vitamin D deficiency are also now being unraveled. This includes immunomodulatory, antitumoral aspects of 25-hydroxy Vitamin D. Various authors have also reported a relationship between low 25-hydroxy Vitamin D levels and adverse outcome of pregnancy including hypertension, gestational diabetes mellitus, preterm delivery and various congenital anomalies. Long-term effects on off-spring health also been seen as an impact of maternal 25-hydroxy Vitamin D levels. ${ }^{12}$ 
Drinking water is another major issue of concern in the context of children's health. Heavy metals, arsenic and fluoride are toxic to fetus, infants and children below 12 years of age. In India, excess fluoride problems have been detected in 20 states and arsenic in two states. A study has been reported regarding serum fluoride levels in neural tube defects and they observed higher levels of fluoride levels in these infants. ${ }^{13,14} \mathrm{~A}$ few studies of human populations have suggested that fluoride might be associated with alterations in reproductive hormones, fertility and Down's syndrome. ${ }^{15}$

It has also been seen in animal studies that supplements of 25-hydroxy Vitamin D3 completely prevented the rachitogenic effects of fluoride. ${ }^{16}$ As fluoride toxicity causes hypovitaminosis $\mathrm{D}$, it may affect the outcome of pregnancy also. The data regarding 25-hydroxy Vitamin D levels in case of adverse outcome of pregnancy especially in congenital anomalies are very less.

No such studies are available in the Indian context, especially in Haryana. Hence the present study was planned to evaluate the level of 25-hydroxy Vitamin D in cord blood in cases of congenital anomalies and its association with cord blood fluoride levels in newborns with visible congenital anomalies in Indian population to collect baseline data so that preventive and diagnostic measures can be planned in environmental health studies for Indian children.

\section{MATERIALS AND METHODS}

The present study was conducted in the Department of Biochemistry in collaboration with the Department of Obstetrics \& Gynecology, Pandit Bhagwat Dayal Sharma PGIMS, Rohtak. The study was ethically approved from the Ethical Committee of the institution. Sixty babies delivered in the labor room were selected for the study. They were divided into two groups. Thirty newborns with visible congenital anomalies were included in group I. Only babies with visible congenital anomalies were taken as inclusion criteria for this group. This group was compared with group II, which were taken as controls and comprised of thirty healthy newborns without any congenital anomalies.

All the patients were subjected to detailed history and clinical examination. Ten $\mathrm{mL}$ cord blood was collected from the placental end of umbilical cord immediately after delivery of the baby. The serum was separated by centrifugation and routine investigations were done on the same day and serum for special investigations was preserved at $-20^{\circ} \mathrm{C}$ till analysis.
- $\quad$ Serum 25-hydroxy Vitamin D was estimated by using Beckman-Coulter kit using RIA method in SR 300 STRATEC. ${ }^{17}$

- Serum Fluoride levels were measured by ion selective electrode (ISE). ${ }^{18}$

Results were expressed as Mean \pm SD and unpaired ' $t$ ' test and Pearson correlation test were applied. Data were considered to be significant if $\mathrm{p}<0.05$.

\section{RESULTS}

Cleft lip ( $\mathrm{n}=7$ ) was the most common congenital anomaly in the present study, while CTEV was the second most common $(n=6)$. Hypospadias, polydactyly, spina bifida showed a similar distribution with three cases each; limb defect (DDH) was seen only in two cases. Omphalocele, anencephaly, gastroschisis, encephalocele, cleft palate and imperforate anus were seen in one case each.

In the present study, serum 25-hydroxy Vitamin D levels were significantly decreased in babies with congenital anomalies as compared to healthy counterparts $(\mathrm{p}=0.000$, Table 1$)$.

Serum 25-hydroxy Vitamin D showed a negative correlation with serum fluoride in both the groups and the association was statistically significant in both groups ( $r=-0.910$ vs. $r=-0.715, p=0.000$, Table 2).

Babies with congenital defects related to the central nervous system and the musculoskeletal system had the lowest serum 25-hydroxy Vitamin D levels and highest serum fluoride levels. Though there was no statistically significant difference in the levels of both the parameters between the groups based on different developmental system (Table 3).

\section{DISCUSSION}

25-hydroxy Vitamin D, which has emerged from its obscure place in science as a forgotten vitamin that was only associated with bone and calcium metabolism to become one of the most celebrated and controversial vitamins/ micronutrients in both medical and lay literature today. ${ }^{19}$

\begin{tabular}{|c|c|c|}
\hline Parameter & Group I $(n=30)$ & Group II $(n=30)$ \\
\hline $\begin{array}{l}\text { Serum 25-hydroxy } \\
\text { Vitamin D (ng/mL) }\end{array}$ & $26.86 \pm .9 .37^{*}$ & $39.91 \pm 10.79$ \\
\hline Range & $7.04-53.35$ & $21.57-72.07$ \\
\hline Serum Fluoride (mg/L) & $0.176 \pm 0.057^{*}$ & $0.055 \pm 0.029$ \\
\hline Range & $0.064-0.264$ & $0.020-0.125$ \\
\hline
\end{tabular}




\begin{tabular}{|c|c|c|c|c|}
\hline Parameter & Group I & $r$ value & Group II & $\mathrm{r}$ value \\
\hline 25-hydroxy Vitamin D (ng/mL) & $26.86 \pm 9.37$ & $p=0.000$ & $39.91 \pm 10.79$ & $p=0.000$ \\
\hline Fluoride (mg/L) & $0.176 \pm 0.057$ & $r=-0.910$ & $0.055 \pm 0.029$ & $r=-0.715$ \\
\hline
\end{tabular}

\begin{tabular}{lcc}
\multicolumn{3}{l}{$\begin{array}{l}\text { Table } 3 \text { : Levels of Serum 25-hydroxy Vitamin D } \\
\text { and Serum Fluoride in different developmental } \\
\text { system }\end{array}$} \\
\hline System involved & $\begin{array}{c}\text { Serum 25-hydroxy } \\
\text { Vitamin D (ng/mL) }\end{array}$ & $\begin{array}{c}\text { Serum } \\
\text { fluoride } \\
\text { (mg/L) }\end{array}$ \\
\hline $\begin{array}{l}\text { Central nervous } \\
\text { system (5) }\end{array}$ & $24.16 \pm 11.11$ & $0.200 \pm 0.060$ \\
$\begin{array}{l}\text { Orofacial defects (8) } \\
\text { Musculoskeletal } \\
\text { defects (13) }\end{array}$ & $27.40 \pm 7.66$ & $0.161 \pm 0.056$ \\
$\begin{array}{l}\text { Gastrointestinal } \\
\text { defects (1) }\end{array}$ & $27.26 \pm 8.15$ & $0.177 \pm 0.056$ \\
$\begin{array}{l}\text { Genitourinary } \\
\text { defects (3) }\end{array}$ & $38.23 \pm 19.09$ & $0.13 \pm 0.086$ \\
\hline
\end{tabular}

25-hydroxy Vitamin D requirements are probably greater in pregnancy, as evidenced by physiologically higher 1, 25-dihydroxy Vitamin D levels seen in the second and third trimesters. While 1,25(OH) $)_{2}$ D levels do not correlate directly with 25-hydroxy Vitamin D concentrations, the physiological rise in the active metabolite, the enhanced intestinal calcium absorption, and enhanced fetal requirement of calcium $(250 \mathrm{mg} /$ day in the third trimester $)$ all point to the importance of 25-hydroxy Vitamin D biology in pregnancy. ${ }^{20}$

In the present study, serum 25-hydroxy Vitamin D levels were significantly decreased in babies with congenital anomalies as compared to healthy counterparts $(\mathrm{p}=0.000$, Table 1).

It has been reported by Specker that deficiency in 25-hydroxy Vitamin D during pregnancy can lead to maternal secondary hyperparathyroidism, tetany, delayed ossification of cranial vertex, enlarged size of fontanelles and impaired fetal bone ossification. ${ }^{20}$ Hyppönen et al reported that there is an association with low 25-hydroxy Vitamin D status and preeclampsia. ${ }^{21}$ Ota et al reported that 25-hydroxy Vitamin D deficiency can be a major risk factor for recurrent pregnancy losses due to an increase in the development of autoimmunity. ${ }^{22}$ In a study by Bodnar et al, it has been seen that a decrease in 25-hydroxy Vitamin D levels may cause spontaneous preterm delivery. ${ }^{23}$ Incidence like high blood pressure in pregnancy, gestational diabetes mellitus, postpartum depression etc. have also been reported in case of low 25-hydroxy Vitamin D status in pregnancy. ${ }^{12}$
In the present study, serum fluoride levels were significantly raised in newborns with congenital anomalies (group I) as compared with newborns without congenital anomalies (group II, Table 1, p=0.000).

Fluoride crosses the placenta and gets incorporated into tissues of developing conceptus. Chronic exposure to high fluoride levels may produce harmful effects on developing fetus especially brain, heart, thyroid and increased future risk of cancer. In recent years, several investigations demonstrated that fluoride can induce oxidative stress and modulate intracellular redox homeostasis, lipid peroxidation and protein carbonyl content, as well as alter gene expression and cause apoptosis. Genes modulated by fluoride include those related to the stress response, metabolic enzymes, the cell cycle, cell-cell communications and signal transduction. ${ }^{24}$

In the present study, serum 25-hydroxy Vitamin D showed a negative correlation with serum fluoride in both the groups and the association was statistically significant in both groups $(\mathrm{r}=-0.910$ vs. $\mathrm{r}=-0.715, \mathrm{p}=0.000$, Table 2$)$. Not only that, we also found that babies with congenital defects related to central nervous system and musculoskeletal system had the lowest serum 25-hydroxy Vitamin D levels and highest serum fluoride levels, though the difference of the levels of these parameters with other groups of congenital anomalies was not statistically significant (Table 3).

In a study done by Khandare et al, it has been reported thathigh fluoride intake can increases the osteoblastic activity causing more consumption of calcium and leading to calcium deficiency. The pathogenesis of various congenital defects in newborns in the present study can be explained by high fluoride intake, which affected the hydroxylation of Vitamin D in liver causing depletion of 25-hydroxy Vitamin D. The low levels of dihydroxycholecalciferol could result from calcium deprivation, which enhances production of dihydroxycholecalciferol sharply leading to depletion of $25(\mathrm{OH})$ D3 stores and thus very high fluoride intake may create secondary 25-hydroxy Vitamin D deficiency. ${ }^{25}$

It has been reported in various studies both in animal models and human models that 25-hydroxy Vitamin D has roles in development and proper functioning of the reproductive system of both male and female individual. 
A study by Bloomberg et al showed that 25-hydroxy Vitamin D has a role in spermatogenesis, sperm maturation and testicular endocrine function. ${ }^{26}$ However, RamlauHanses et al showed no effects of 25-hydroxy Vitamin D on these physiological processes. ${ }^{27}$ Another study by Ott et al showed that 25-hydroxy Vitamin D also regulate the female reproductive system and deficiency of 25-hydroxy Vitamin $\mathrm{D}$ is associated with lower rates of follicle development. ${ }^{28}$

Adequate nutritional 25-hydroxy Vitamin D status during pregnancy is important for fetal development, tooth enamel formation and general fetal growth. ${ }^{29,30}$ Mansion et al found that intake of 25-hydroxy Vitamin D during pregnancy caused an increase in birth weight of the babies. ${ }^{31}$ In another study by Pawley et al, it has been found that cord blood 25-hydroxy Vitamin D concentration has a significant association with head circumference at 3 and 6 months of age. ${ }^{32}$ Meghbooli et al also found significantly wider posterior fontanelle diameter in newborns of mothers with 25 - hydroxy Vitamin Deficiency. ${ }^{33}$ Maternal 25-hydroxy Vitamin D deficiency has been linked to a predisposition to a spectrum of infectious etiologies including periodontal disease, bacterial vaginosis and HIV morbidity and mortality associated with opportunistic illnesses. ${ }^{34}$ The findings of our study in terms of the adverse outcome of pregnancy are in association with these studies.

\section{CONCLUSION}

Environmental pollutants like fluoride have the potential to interact with various micronutrients like 25-hydroxy Vitamin D and can cause the deficiency of it. This can ultimately cause various adverse fetal outcomes. The exact mechanism of this interaction is yet to be fully explored. Several areas of research have suggested a role of maternal 25-hydroxy Vitamin D during pregnancy on growth and development of the offspring. Recent evidence demonstrates that the prevalence of 25-hydroxy Vitamin D deficiency in women of child-bearing age is surprisingly high. However, the role of 25-hydroxy Vitamin D deficiency on fetal development during pregnancy has not been wellcharacterized. Low vitamin D serum levels in association with high serum levels of fluoride can be associated with increased risk of congenital anomalies. So, further studies are needed to determine the serum levels and the degree of supplementation of 25-hydroxy Vitamin D, that is required to optimize maternal and fetal outcomes.

\section{ACKNOWLEDGEMENT}

We would like to express our sincere gratitude to our guides Dr. Simmi Kharb and Dr. Smiti Nanda for their continuous support and guidance.

\section{REFERENCES}

1. National family health survey (NFHS-3) 2005-06. Mumbai: International Institute for Population Sciences (IIPS) and Macro International. 2009. Available from: http://www.rchiips.org/nfhs/ nfhs3.shtml [Accessed 11 ${ }^{\text {th }}$ November 2017].

2. Ghosh S. Down syndrome in India. Br Med J 1967; 3:309. https://doi.org/10.1136/bmj.3.5560.309

3. Weatherall DJ and Clegg JB. Inherited haemoglobin disorders: An increasing global health problem. Bull World Health Organ 2001; 79:704-712.

4. Dekaban A, O'rourke J and Cornman T. Abnormalities in offspring related to maternal rubella during pregnancy. Neurology 1958; 8:387-392. https://doi.org/10.1212/WNL.8.5.387

5. Wright Jr HT. Congenital anomalies and viral infections in infants-the etiologic role of maternal viral infections. Calif Med 1966; 105:345.

6. World Health Organisation. Congenital Anomalies Fact sheet. Available from: http://www.who.int/mediacentre/factsheets/ fs370/en/[Accessed 11 th November 2018].

7. Berry RJ, Bailey L, Mulinare J, Bower $\mathrm{C}$ and Dary O. Fortification of flour with folic acid. Food Nutr Bull 2010; 31:22-35. https://doi. org/10.1177/15648265100311S103

8. Källén K. Multiple malformations and maternal smoking. Paediatr Perinat Epidemiol 2000; 14:227-233. https://doi. org/10.1046 j.1365-3016.2000.00269.x

9. Mithal A, Wahl DA, Bonjour JP, Burckhardt P, Dawson-Hughes B, Eisman JA, et al. Global 25-hydroxy Vitamin D status and determinants of hypovitaminosis D. Osteoporos Int 2009; 20:1807-1820. https://doi.org/10.1007/s00198-009-0954-6.

10. Sahu M, Bhatia V, Aggarwal A, Rawat V, Saxena P, Pandey A, et al. 25-hydroxy Vitamin $D$ deficiency in rural girls and pregnant women despite abundant sunshine in northern India. Clin. Endocrinol (Oxf) 2009; 70:680-684. https://doi. org/10.1111 j.1365-2265.2008.03360.x

11. Dasgupta A, Saikia U and Sarma D. Status of $25(\mathrm{OH}) \mathrm{D}$ levels in pregnancy: A study from the North Eastern part of India. Indian J Endocrinol Metab 2012; 16: S405-S407. https://doi. org/10.4103/2230-8210.103020

12. Mithal $A$ and Kalra S. 25-hydroxy Vitamin D supplementation in pregnancy. Indian J Endocrinol Metab 2014;18:593.

13. Ratan SK, Rattan KN, Pandey RM, Singhal S, Kharab S, Bala M, et al. Evaluation of parental folate, vitamin B12, fluoride and homocysteine levels in the newborns with neural tube defects (NTD). $20^{\text {th }}$ Congress of Asian Association of Pediatric Surgeons (AAPS) with WOFAPS Executive Meet, New Delhi. 2006: p 59.

14. Ratan SK, Rattan KN, Pandey RM, Singhal S, Kharab S, Bala M, et al. Evaluation of the levels of folate, vitamin B12, homocysteine and fluoride in the parents and the affected neonates with neural tube defect and their matched controls. Pediatr Surg Int 2008; 24:803-808. https://doi.org/10.1007/s00383-008-2167-z

15. Hanley TR Jr, Calhoun LL, Kociba RJ and Greene JA. The effects of inhalation exposure to sulfuryl fluoride on fetal development in rats and rabbits. Fundam Appl Toxicol 1989; 13:79-86. https:// doi.org/10.1016/0272-0590(89)90308-4

16. Kumar N, Sood S, Arora B and Singh M. To study the effect of 25-hydroxy Vitamin $D$ and $E$ on sodium-fluoride-induced toxicity in reproductive functions of male rabbits. Toxicology International 2012; 19:182. https://doi.org/10.4103/0971-6580.97220

17. Burns R, Immunochemical techniques In: Wilson K, Walker J (eds.) Principles and Techniques of Biochemistry and Molecular Biology Cambridge University Press Cambridge 2010: pp 263299. https://doi.org/10.1017/CBO9780511841477.008

18. Venkateswarlu P. Evaluation of analytical method for fluorine in 
biological and related materials. J Dent Res 1990; 69:514-521. https://doi.org/10.1177/00220345900690S105

19. Maxmen A. 25-hydroxy Vitamin D on trial. The Scientist 2012; 26:44-50. https://doi.org/10.1016/S0262-4079(12)60968-3

20. Specker BL. Does 25-hydroxy Vitamin D during pregnancy impact offspring growth and bone? Proc Nutr Soc 2012; 71:38-45. https://doi.org/10.1017/S0029665111003053

21. Hyppönen E, Cavadino A, Williams D, Fraser A, VereczkeyA, Fraser WD, et al. 25-hydroxy Vitamin $D$ and pre-eclampsia: Original data, systematic review and meta-analysis. Ann Nutr Metab 2013;63:331-340. https://doi.org/10.1159/000358338

22. Ota K, Dambaeva S, Han AR, Beaman K, Gilman-Sachs A and Kwak-Kim J. 25-hydroxy Vitamin $D$ deficiency may be a risk factor for recurrent pregnancy losses by increasing cellular immunity and autoimmunity. Hum Reprod 2014;29:208-219. https://doi.org/10.1093/humrep/det424

23. Bodnar LM, Klebanoff MA, Gernand AD, Platt RW, Parks WT, Catov JM, et al. Maternal 25-hydroxy Vitamin D status and spontaneous preterm birth by placental histology in the US Collaborative Perinatal Project. Am J Epidemiol 2014; 179:168-176. https://doi.org/10.1093/aje/kwt237

24. Ghosh A, Kharb S and Nanda S. Evaluation of Association of Cord Blood Fluoride Levels with Visible Congenital Anomalies in Newborns. Int J Adv Res Dev 2018; 3:95-100.

25. Khandare AL, Harikumar R and Sivakumar B. Severe bone deformities in young children from 25-hydroxy Vitamin D deficiency and fluorosis in Bihar-India. Calcified Tissue International 2005; 76:412-418. https://doi.org/10.1007/s00223005-0233-2

26. Blomberg Jensen $M$, Jørgensen $A$, Nielsen JE, Bjerrum PJ, Skalkam M, Petersen JH, et al. Expression of the 25-hydroxy Vitamin D metabolizing enzyme CYP24A1 at the annulus of human spermatozoa may serve as a novel marker of semen quality. Int J Androl 2012; 35:499-510. https://doi. org/10.1111 j.1365-2605.2012.01256.x

27. Ott J, Wattar L, Kurz C, Seemann R, Huber JC, Mayerhofer K, et al. Parameters for calcium metabolism in women with polycystic ovary syndrome who undergo clomiphene citrate stimulation: a prospective cohort study. Eur J Endocrinol 2012:EJE-11. https://doi.org/10.1530/EJE-11-1070

28. Ramlau-Hansen $\mathrm{CH}$, Moeller UK, Bonde JP, Olsen $\mathrm{J}$ and Thulstrup AM. Are serum levels of 25-hydroxy Vitamin D associated with semen quality? Results from a cross-sectional study in young healthy men. Fertil Steril 2011; 95:1000-1004. https://doi.org/10.1016/j.fertnstert.2010.11.002

29. Brooke OG, Brown IRF and Bone CDM. 25-hydroxy Vitamin D supplements in pregnant Asian women: effects on calcium status and fetal growth. Br Med J 1989; 1:751-754. https://doi. org $/ 10.1136 / \mathrm{bmj} .280 .6216 .751$

30. Brooke OG, Butters F and Wood C. Intrauterine 25-hydroxy Vitamin D nutrition and postnatal growth in Asian infants. Br Med J 1981; 283:1024. https://doi.org/10.1136/bmj.283.6298.1024

31. Mannion CA, Gray-Donald K and Koski KG. Association of low intake of milk and 25-hydroxy Vitamin $D$ during pregnancy with decreased birth weight. Canadian Medical Association Journal 2006;174:1273-1277.

32. Pawley $\mathrm{N}$ and Bishop NJ. Prenatal and infant predictors of bone health: the influence of 25 - hydroxy Vitamin D. Am J Clin Nutr 2004; 80:1748S-1751S. https://doi.org/10.1093/ajcn/80.6.1748S

33. Maghbooli Z, Hossein-Nezhad A, Shafaei A, Karimi F, Madani F and Larijani B. 25-hydroxy Vitamin D status in mothers and their newborns in Iran. BMC Pregnancy Childbirth 2007; 7:1. https:// doi.org/10.1186/1471-2393-7-1

34. Luk J, Torrealday S, Neal Perry G and Pal L. Relevance of 25-hydroxy Vitamin D in reproduction. Hum Reprod 2012; 27:3015-3027. https://doi.org/10.1093/humrep/des248

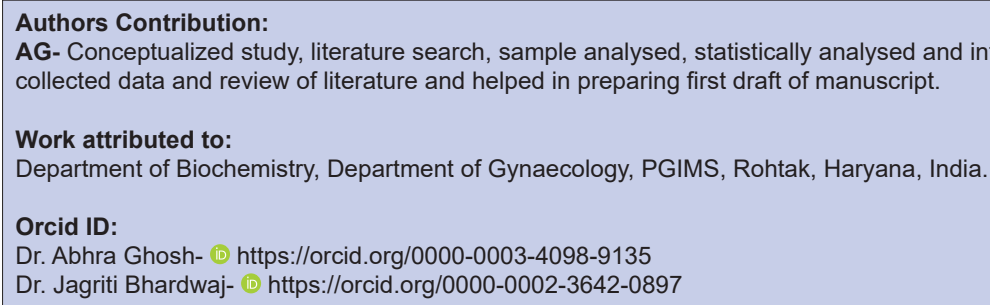

